\title{
Is the pedestrian city relevant to the sustainable city? Mobility, urbanization and health
}

\author{
K. Maikov ${ }^{1} \&$ M. Pihlak ${ }^{2}$ \\ ${ }^{I}$ Landscape Architecture Program, Estonian University of Life Sciences, \\ Estonia \\ ${ }^{2}$ Department of Landscape Architecture, Pennsylvania State University, \\ USA
}

\begin{abstract}
For the past one hundred years American style automobile oriented urban development has swept the world. Estonia has adopted free market capitalism and is on the verge of adopting American style automobile dominated development patterns. The tradition of Nordic style planning has ameliorated the American style automobile domination. Small town Pennsylvania, USA as exemplified by the college town of State College, PA is still firmly in the grip of the traffic oriented transportation planner. The big city innovations of pedestrian priority areas and new urbanism have not penetrated to the American hinterlands. Keywords: pedestrian, walking, urban design, obesity, Estonia, sidewalks, Pennsylvania, Toronto.
\end{abstract}

\section{Introduction}

The automobile domination of the American City is almost complete (Kuntsler [1-3], Holtz Kay [4]). Post soviet era Estonia is producing similar automobile dominated suburban commercial landscapes. This automobile oriented development pattern is so destructive of traditional urban form that in the United States special national planning initiations are necessary to ensure that children will be able to walk to neighbourhood schools (Safe Routes to School). Safe Routes to Schools is a popular program spreading across Canada and the U.S. designed to decrease traffic and pollution and increase the health of children and the community. The program promotes walking and biking to school through education and incentives [5]. 
This automobile domination is best illustrated in the commercial landscape of big box retail and enclosed regional shopping mall development in suburban locations which generally eliminate sidewalks and pedestrian crossings in favour of speeding vehicular traffic. This automobile dominated landscape contributes to the lifestyle choices, which can lead to obesity and poor health. Central Pennsylvania has the highest obesity rates in the United States. "Obesity is a complex, multi-factorial chronic disease involving environmental (social and cultural), genetic, metabolic, behavioural and psychological components. It is the second leading cause of preventable death in the U.S." [6]. A healthy life style includes regular pedestrian activity. It is estimated that an average person is required to take 10,000 steps to burn the average calorie intake. It has been found out that town-dwellers of all ages, i.e. children, adults, and elderly people, are, on average, able to walk 204 meters in five minutes. If the elderly inhabitants are excluded, the rate is 294 meters in five minutes, and if the children are also excluded, the rate for adult town-dwellers is 325 meters in five minutes [7]. For the average US resident this level of pedestrian activity is difficult to achieve. One of the authors (Pihlak M) regularly achieved less than eight thousand daily steps, even with walking regularly to work and two daily dog walks. Most Americans do not walk this much and thus risk weight gain. Is this the Estonian future? Access to green landscapes improves overall life satisfaction and wellbeing (Kaplan [8]). In Estonia the green landscape is used for pedestrian movement. A safe and continuous pedestrian environment is one of the factors in encouraging pedestrian movement. The case study of the area planning and pedestrian movement between The Nittany Valley Mall and the Benner Pike Walmart Super Centre will illustrate the common American area planning trend of ignoring the pedestrian in favour of vehicular traffic. In the Nittany Mall example pedestrian movement is actually prohibited. The case study of pedestrian movement in the city broadens to the apartment building areas in Tartu will illustrate the Estonian approach to automobile orientation. This is a typical commercial suburban development.

\section{Pedestrian safety and amenity hierarchy}

“....the definition of Pedestrian [level of service] LOS does not include anything about mobility (except for the possibility of running into another pedestrian) nor safety. This is an inherent bias of the LOS that strongly favours automobiles over pedestrians."'[9]

In the United States transportation planning is almost exclusively vehicular oriented. Whatever pedestrian standards do exist they are relatively coarse, with assumptions that pedestrians are clearly a secondary concern to vehicular traffic. In the Greater Hamilton Area (GHA), Canada, pedestrian call buttons immediately stop traffic when pushed by the pedestrian.

A simple listing of pedestrian oriented questions can establish the level of pedestrian concern at the site level. 
1. Simple Access. Can I cross the street?

2. Safety. Is it safe to cross the street? Can I make it to the other side of the street before the pedestrian crossing light turns red?

3. Amenity. Is it pleasant to cross the street? Is there enough time to cross the street comfortably without being menaced by turning vehicles?

4. Priority. Pedestrian walk button immediately stops vehicular traffic. “Justification. The No Pedestrian Crossing Sign ,R9-3, shall be authorized for use to prohibit pedestrians from crossing a roadway at a point which is considered to be hazardous, or when provisions for a pedestrian crossing at a signalized intersection have not been provided."([10]). For a healthy urban area this no pedestrian crossing sign should be rarely seen. For the sign to be used in the major regional shopping mall prohibiting pedestrian access from a busy book store to the regional mall is inexcusable. The Greater Toronto Area (GTA), Canada has the greatest legal support for pedestrian accessibility. The street car system, run by the Toronto Transit Commission, (TTC) necessitates automobile controls that give the pedestrian priority when entering or exiting a street car. This system extends to intersections that do not have stoplight control. At these intersections there is an over head yellow light and signage that require vehicles to stop when a pedestrian points their index finger cross the street. Pedestrian merely points finger across road and cars come to a screeching halt. Drivers lose two demerit points on their Ontario driving licence if they are caught failing to stop for pedestrians. Once they lose eleven points their driving licence is revoked. In the nearby Hamilton Greater Area (HGA) certain pedestrian crossing buttons will immediately trigger the walk signal and stop crossing traffic. This occurs on the access road to one of the limited access mid-escarpment roadways. No US city has this level of pedestrian priority street crossing.

\section{Copenhagen, Denmark}

The world leader with regard to pedestrian rights is Copenhagen, Denmark. Since 1962 Copenhagen began banning vehicles from the centre of the historic city. Jan Gehl has documented the successful pedestrianization of previously vehicular oriented roads and car parks within the historic city (Gehl [11]).

Anti pedestrian intersections. If there is no space for pedestrians to walk then they will not walk. If it is extremely unpleasant to walk they will be discouraged from walking. These are pedestrian truisms.

\subsection{Pedestrian friendly infrastructure}

Pedestrian activity is more than doubled if pedestrian facilities are provided. Traffic engineers and urban planners rarely receive adequate training related to non-motorized transportation. Only one out of a hundred highway professionals has taken a college course on non- motorised transportation and these courses were offered in overseas colleges. Federal policy now links pedestrian and bicycle access with funding. Six criteria are required: connectivity, linkage with 
other modes, fine grained land use patterns, safety, visual quality and pedestrian path context. Engineering, planning and design collaboration is needed to implement the goal of walkable cities.

\subsection{Walking contrast between Estonia and USA}

The inhabitants of Tartu divide quite evenly between different transportation modal groups. Almost $43 \%$ of them go to work and/or school by bus, $29 \%$ on foot, $26 \%$ by car, and $2 \%$ mostly by bike. By contrast the US in general has much less transit usage. "Public transit use peaked in 1946, when Americans took 23.4 billion trips on trains, buses and trolleys...By 1960, that figure had dropped to 9.3 billion, and it declined further as roads and car culture gripped the nation. In 1972, transit ridership hit rock bottom at 6.5 billion trips. Since then, it seesawed until 1995, when it began steadily climbing." [12].

Within the State College region "public transit use is over 3\%. Surrounding communities are at $2 \% "$ " [13].

In Estonia the average inhabitant of Tartu spends 21 minutes to reach workplace; there are no great differences between different sections of the town. However the speed depends on the way of travelling. It takes 17 minutes on foot, 14 by car but twice as long by bus -29 minutes. The best possibilities for pedestrians are in Annelinn, Tähtvere and Vaksali sections. The most negative evaluation has been given to parking arrangements near abodes. In 5-point scale (1-extremely poor, 5 -excellent) the general evaluation to parking opportunities near abodes is 2.6 . $11 \%$ inhabitants mention parking opportunities and the condition of roads as the worst organized fields in town. Extremely poor are the possibilities to park near abodes, the condition of roads and pavement are quite bad. Still the safety of routes to schools is not a big problem in Tartu. Only 14\% of inhabitants have said their children's routes to school are dangerous [14].

Tartu has quite many possibilities to move around. Persons who like to move themselves are the main offers of such possibilities. For example there are routes to observe and listen to birds in city centre, three footpaths outside town limits introducing architectural values of the surrounding. Footpaths must always educate the ones using it. The footpaths are called Karlova, Supilinn and Toometagune. It is strange that the area surrounding river Emajõgi (it is separated from the Old Town area by Vabaduse Street) is not considered to be a footpath. Tartu's biggest park Toomemägi also has many possibilities for walking, people enjoy being there. The footpaths go through Tartu's historical sights. The future trend is that city centres (also known as pedestrian sections) should have different thematic streets - streets of restaurants, shops, books, clothes, beauty etc.

The pedestrian section of Tartu is relatively quiet and could be meant more for tourists and walkers. Outside the town limits, following the banks of river Emajõgi is Jänese footpath. It is a 5-kilometre easily penetrable path for hikers and walkers. Within town limits there is not yet a network of footpaths. However the city council has strong proposals about it and family parks are under design. 


\subsection{Apartment buildings}

Soviet era apartment buildings are similar everywhere and the older ones follow the same soviet rule - as little space per person as possible and mentality "we ask nothing from nature we just take what we need". As a result the buildings are designed so close to each other that the sites plan is outbalanced. Centrally the playschool, then primary school and basic school were created in the middle of a town section. Only green areas were the surroundings of playschools and schools where children and teenagers from every age group gathered. Pavements around buildings were not designed, the area was left open and in 2-3 years pedestrians just walked the paths into lawn areas and then these paths were covered with asphalt. These bedroom suburbs built in 1970's were based on public transportation. As time went by people began to own more cars but this development was not supported by the conception. Therefore in the mornings there are big impasses on the narrow streets and in the evenings parking difficulties. All this lack of natural landscapes excludes the need for walking. That in turns leads to abiding only to one's own apartment, which is in close relations with stress. All results in declining public health (gormandise, decreased ability to act).

People have started using sports centres to compensate the lack of movement. This kind of lifestyle causes rapid life pace which exhaust the organism and exercising is fooling your organism because the energy necessary for recovery is in natural landscapes. The only walking is from the house to bus stop and back and taking out the rubbish. Cars have become commodity and all necessary rides are taken by car. If you would really want to then it would be possible to go jogging around apartment buildings and schools/playschools. Walking at a moderate pace for 30-60 minutes burns stored fat and can build muscle to speed up your metabolism. Walking an hour a day is also associated with cutting your risk of heart disease" [15].

\section{Inhabitant sections}

In city planning the pressure by owners of private property is so great that city officials cannot afford to keep land for designing green areas. Also the fragmentation of sites allows approaching the sites individually therefore general planning is necessary to determine the amount of green areas. Officials who solve these problems are not qualified enough. These bedroom suburbs cause problems in vehicular traffic because there are not enough parking spaces and streets are narrow. In inhabitant sections the relative importance of available land is $60-80 \%$. That land can be used for designing natural environment. Mostly these sections are about 30 years old and have trees already (1-2 trees per site as a rule). Usually the sites are surrounded by some kind of hedge. In private house areas usually there are no natural environments for public use. Because of that people's movement is limited - they move in the limits of their own sites. On the plus side there is more greenery. The roads there have less traffic and therefore more opportunities for pedestrian movement. Diffusion of negative ions and 
energy gives the impression that private house areas are ideal living environments where everybody wants to be. Areas where the sites are under $1500 \mathrm{~m}^{2}$ are considered to be bedroom suburbs. There the access roads are the biggest problem. Also these areas do not have unitary design and architects can do what they want. This is why these areas are called "the idiot villages"

\section{Dangers}

Big shopping centres force people to travel by car because visiting those gives opportunity to buy everything from one place and are accessible only by cars or public transportation. In the city centre the biggest road is Vabaduse Street, which for pedestrian is impossible to cross in rush hours. Surveys have also proved that people tend to visit banks more at the shopping centres and therefore the small branch offices are closed. In the edges of the city centre the extensions of shopping centres are all built to Turu Street but the same situation occurs there are only two possibilities to cross the street. The street itself is four-lined. Some shopping centres are on the outskirts of Tartu and accessible only by car. Because of this free access to city centre people travel only by car and enjoy weather only through windows. Lõunakeskuse shopping centre is a classical example of not bothering about pedestrians. The speed limit there is $70 \mathrm{~km} / \mathrm{h}$ and pedestrians are led from pavement to highway without a pedestrian crossing so crossing the highway is hazardous. It is a temporary solution until Tallinn Luhamaa highway is finished but that could take years and people have to move there every day. The areas next to highways are also dangerous.

\section{Conclusion}

"Pedestrian-oriented site planning and design can contribute much to the convenience, comfort and enjoyment of daily activities. In addition, energy conservation necessitates reduced dependence on the automobile and encouragement of pedestrian and other energy-efficient alternatives" [16]. Even the US Army has discovered the benefits of a direct and cohesive pedestrian environment. Small town Pennsylvania as exemplified by the State College centred region is still in the grip of a vehicle only transportation planning mentality. Tartu, Estonia has the advantage of a long pedestrian history yet the Soviet Era and the modern capitalist era runs the risk of embracing a vehicular orientation and a lack of pedestrian delight.

Another federal agency, the Federal Highway Administration has also attempted to increase professional concern for the pedestrian and cyclist. However "Studies have shown that as per capita income rises, people switch to private motor vehicle ownership and the extent of walking and bicycling decreases." Estonia is clearly going through this per capita income increase process. A balance needs to be found where the need for vehicular roadway capacity is balanced with the needs of a cohesive and amenity rich pedestrian environment. The Canadian cities of Toronto and Hamilton have shown that the needs of the pedestrian need not be sacrificed in accommodating vehicular needs. 
Jan Gehl and the City of Copenhagen have shown that it is a question of urban design values as how space should be allocated for pedestrians and vehicles. A balanced transportation system that includes the pedestrian saves energy provides future flexibility for new rapid transit options creates superior urban form and improves the health and satisfaction of urban dwellers.

\section{References}

[1] Kuntsler J H. The Geography of Nowhere: The Rise and Decline of America's Man-Made Landscape 1994

[2] Kuntsler J H. Home From Nowhere Simon and Schuster, New York 1998

[3] Kuntsler J H. The City in Mind: Notes on the Urban Condition, Simon and Schuster, New York,2003.

[4] Holtz Kay. Asphalt Nation: How the Automobile Took Over America and How we can take it Back, UC Press Berkeley, 1998

[5] http://www.saferoutestoschools.org/, 03.04.2006

[6] Obesity.org 2006

[7] The Urban Traffic Network 1975 Sweden

[8] Kaplan 2001 The Nature of the View from Home. Psychological benefits. Environmental \& Behaviour 33 (4):507-542

[9] http://www.walksf.org/pedestrianLOS.html

[10] http://www.dot.state.pa.us/

[11] Gehl, J. The Life Between Buildings, Danish Architectural Press, 2003

[12] http://www.commondreams.org/headlines/043000-01.htm, 03.04.2006

[13] http://www.catabus.com/board/minutes/2003/82503.htm, 03.04.2006

[14] http://www.tartu.ee/?lang id=1\&menu id=2\&page id=1136, 03.04.2006

[15] http://walking.about.com/cs/howtoloseweight/a/walkoffweight.htm, 03.04.2006)

[16] US Army Area Planning,Site planning and Design p 762004 